\title{
GENERALIZED VACCINIA IN PATIENTS WITH PEMPHIGUS FOLIACEUS
}

\author{
Luis F. de Salles-Gomes, M.D. \\ S. Ivo Rabello, M.D. \\ Antonio Amorosino, B.S. \\ Carlos A. A. Pederneiras, M.D. \\ Instituto Adolfo Lutz, São Paulo, Brazil
}

Filomena

B. Magaldi-Jordão, B.

Juan J. Angulo, M.D.

Although there are numerous reports of individual cases, only a few papers deal with general aspects of the clinical picture of generalized vaccinia (Tedder, I936; Clark, Seiler, Joe, Gammie, Tait and Jack, 1944; Fries, Borne and Barnes, 1948). During two outbreaks of generalized vaccinia occurring, after two mass vaccinations, in a hospital for patients with pemphigus foliaceus, some clinical observations were made from time to time while more clinical data could be collected in retrospect. Despite its limitations, the evidence so obtained is presented in this paper in view of the paucity of the pertinent literature.

\section{Methods and Material}

The clinical observations recorded in the present paper were made in a total of 47 cases of generalized vaccinia, all of whom were suffering from pemphigus foliaceus, except for one who had atopic dermatitis. Clinical data could not systematically be obtained from the patients because none of the authors was associated with the Hospital, transportation was not easy and the chief aim of the visits to the Hospital was the study of the epidemiology of vaccinia. Thus, a clinical examination or short follow-up was occasionally made in a number of patients while certain clinical characteristics were retrospectively investigated in groups of patients in the fashion proper to epidemiological surveys. The Hospital clinical histories referred exclusively to pemphigus foliaceus, except for temperature records in patients feeling very ill. Some information obtained in retrospect was neglected because of unreliability, or could not be obtained at all due to poor memory or lack of recording. All these facts explain why the observations of individual manifestations are based upon different numbers of patients.

The clinical diagnosis of individual cases was essentially based upon the following criteria: pock morphology; distribution of skin lesions, especially in regard to 'take '; time of appearance in relation to 'take' or to vaccination of wardmates and clinical course, particularly in regard to 'take'. Epidemiological data, especially the occurrence of two 'explosive' outbreaks after two mass vaccinations and other evidence were employed in the clinical diagnosis of individual cases. Finally, virus isolation and/or antibody titration confirmed the diagnosis in 24 of the 47 cases observed.

A point deserving comment is the ability of patients with pemphigus foliaceus to discriminate between vaccinial pocks and the lesions of their previous, chronic condition. Hospitalized for years and having no compulsory activity to divert their attention, thes become most meticulous observers, searching for the presence of new lesions as well as for the evolution of the old ones. When questioned about the vaccinial eruptión, the patients spontaneousiy pointed out the differences between vaccinial pocks and the larger, flaccid bute of pemphigus foliaceus whose thin roofs easily tore down releasing their fluid content. Besides, the conceign caused by the outbreaks made each patient watch cargfully for the appearance of vaccinial lesions not only in himself but in his wardmates as well. Information repeatedly confirmed by questioning wardmates, nurses and physicians as well as by cross-questioning te patient surveyed and consulting the hospital records.

\section{Systemic Manifestations}

A vaccinial eruption is accompanied by sligîgt $\overrightarrow{\text { off }}$ any constitutional reaction in some cases whike th others, intense systemic manifestations are for (Curth and others, 1948). Constitutional upset $\vec{m}$ 离 be slight or non-existent at the onset of the exanth but becomes prominent during the eruption, least in cases of eczema vaccinatum (Fries, Bor and Barnes, 1948).

\section{Prodromal Period}

The time-relationship of the onset of systemin manifestations to that of the exanthem is net usually distinguished in the literature. Clan and others (1944) employed the absence of a preeruptive illness as a characteristic of both 'generalized ' vaccinia and ' autogenous' vaccinga in the differentiation from smallpox. Apparenty a prodromal period may not exist in some cases although little if any attention has been paid tosa symptomatology ushering in the exanthem. 을.

In the present study, no information regarding pre-eruptive illness was systematically collected but since the dates of onset of fever and rash weare recorded in nine cases of generalized vaccinia, the occurrence of a febrile illness ushering in the eruption could be established in three of these nine cases. This pre-eruptive fever lasted on three and three days respectively.

Fever

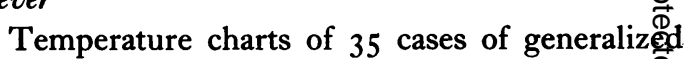


vaccinia were available. In $72 \%$ of these cases, fever reached $39^{\circ} \mathrm{C}$. (102. ${ }^{\circ} \mathrm{F}$.) or more at least once. Except for two cases with intermittent fever, the latter occurred continuously for periods ranging from one to 21 days with a mean of 10.2 days. As said before, fever had its onset before the appearance of the exanthem in three of the nine cases where the corresponding dates were recorded while in the other six cases, fever appeared during the eruption.

Some of the 35 cases whose temperatures were charted and several other patients, as well as their wardmates and nurses, were questioned to determine the occurrence of a number of systemic manifestations usually found in generalized vaccinia including, indeed, a feverish state. The latter was reported by 29 out of the 32 cases questioned and this makes fever the most frequent symptom among cases of generalized vaccinia. Furthermore, in three of these 29 cases, a feverish state was the only complaint.

TABLE I

Frequency of Systemic Manifestations in 32 Cases OF GENERALIZED VACCINIA

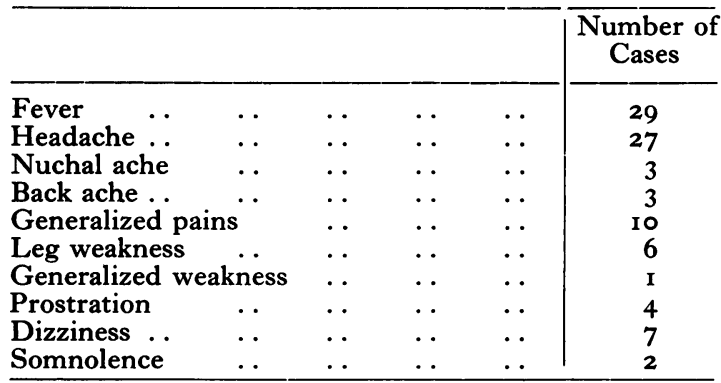

\section{Headache and other Manifestations}

Headache was another symptom almost constantly reported by cases of generalized vaccinia. Twenty-seven of the 32 cases reporting systemic manifestations suffered from headache. The latter was accompanied by nuchal ache in three cases. In three patients, headache was present in the absence of fever, the most frequent of all symptoms. All three cases reporting pains referred to the back of the trunk also suffered from headache. Only one of the ten cases complaining of generalized pains did not report headache.

Four of the 32 cases suffered from prostration; one case reported generalized muscular weakness and six other cases remarked weakness of their leg muscles. Evidence of a definite neurological syndrome was observed in two cases. One of the latter, besides headache and nuchal ache, had somnolence and the other suffered from dizziness, somnolence, headache and leg weakness. These symptoms dominated the clinical picture so that fever was the only other manifestation in both cases. Five of the 16 females reported dizziness while only two of the 16 males did.

Ten of the 32 cases of generalized vaccinia questioned about systemic manifestations reported a few of these and denied others. Fever and headache were the only symptoms in three of these cases; three patients felt fever alone, two cases suffered from headache and nuchal ache with no other manifestation; another case had headache and generalized pains and the remaining case reported only fever and muscular weakness.

The intensity and constancy of the systemic manifestations were striking even in patients with a rather scanty vaccinial exanthem. This finding probably is significant and perhaps determined, at least in part, by pemphigus foliaceus since Curth, Curth and Garb (1948) found little if any constitutional upset in cases of generalized vaccinia who had no chronic pre-existing disease while the reverse was true in their patients who previously had eczema. It seems that systemic manifestations do not constitute a reliable index of vaccinial infection.

\section{The Exanthem \\ Pock Morphology}

The stages of pock formation and regression in a given individual could not be followed for reasons already explained. Besides, only pustules were usually found when the patients were seen. Vaccinial pocks characteristically become pustules very early, at least, earlier than in smallpox and chickenpox; a fact typically occurring during the present study. Nevertheless, a wide range of variation in pock morphology was noticed. The size of the lesions varied even in the same body region of a given individual and the same was true of their appearance. Some pocks showed a raised whitish ring surrounded by a necrotic centre usually covered by scabs such as it is typically seen in ten-day old primary vaccination 'takes', for instance. These lesions sometimes coalesced with neighbouring pocks forming large patches covered by a purulent exudate. At times, round, convex lesions resembling the gunshot appearance of the classical variolous pock were found and such lesions apparently did not later acquire the appearance of vaccination ' takes'. Both types of pock morphology were seen in the same region, the back of the trunk, for instance, in areas separated by only a few centimetres. Apparently, this phenomenon was not the consequence of crops appearing at different times. Pock umbilication was a frequent finding while some lesions showed a darker centre but no depression. A case was observed showing round papular pocks, apparently without liquid content. 
Some time after the outbreaks, but not during the latter, several patients suffered from what they graphically called 'pimples' which they easily discriminated from the characteristic vaccinial lesions prevailing during the outbreaks as well as from the bullæ proper of pemphigus foliaceus. According to their description, such lesions probably were abortive vaccinial pocks which reached the papular or vesicular stages without undergoing pustulation.

\section{Pock Distribution}

The localization of vaccinial pocks was determined in 29 patients with pemphigus foliaceus and in one individual with chronic atopic dermatitis. In the latter patient and in 13 of the patients previously suffering from pemphigus foliaceus, the vaccinial pocks were found all over the body. In 16 of the 29 patients with previous pemphigus foliaceus a patchy distribution of vaccinial lesions was evident. In these 16 cases, the body regions involved were those found in Table 2 . The arm was the region most frequently attacked by generalization pocks. The other regions more frequently attacked were the face, the leg and the back of the trunk (Table 2).

TABLE 2

Areas Involved by Eruption in in Cases of Generalized Vaccinia*

\begin{tabular}{|c|c|c|c|c|c|c|}
\hline & & & & & & $\begin{array}{c}\text { Number of } \\
\text { Cases }\end{array}$ \\
\hline Arm & . & $\ldots$ & $\ldots$ & .. & . & 10 \\
\hline Face & .. & .. & . & .. & .. & 6 \\
\hline Leg & .. & .. & . & $\ldots$ & . & 5 \\
\hline Back & .. & .. & .. & .. & .. & 5 \\
\hline Chest & $\ldots$ & .. & .. & .. & .. & 2 \\
\hline Abdomen & .. & .. & .. & .. & .. & 2 \\
\hline Head & . & .. & . & . & .. & I \\
\hline Flank & .. & .. & .. & . & .. & I \\
\hline Buttock & .. & .. & .. & . & .. & I \\
\hline Foot & $\ldots$ & $\ldots$ & .. & $\ldots$ & .. & I \\
\hline Elbow & .. & .. & .. & .. & .. & I \\
\hline
\end{tabular}

*More than one area usually involved.

Sometimes, only one extremity was attacked. In these cases, if the patient was vaccinated the arm involved was that with the 'take'. There were three cases who showed pocks in only one region: the foot, the elbow and the face, respectively. A similar selectivity for certains body regions was noticed by Fonzari (1952) during the outbreak of generalized vaccinia occurring in $195^{2}$ in the same pemphigus foliaceus hospital where the present observations were made in 1956. Fonzari constantly noticed involvement of the face and the neck and remarked that in an appreciable portion of the cases observed by him, the eruption did not involve the whole body but pocks were found in regions like the shoulder, arm and thorax की the neighbourhood of the vaccination site. U fortunately, Fonzari did not report numerical daea.

Pocks were found isolated or coalesced with neighbouring pocks. In severe cases, the dividuality of lesions usually was not well defined because of proximity and septic complications byt some cases with scanty exanthem exhibited large patches formed through coalescence. Besides, even in the same patient, coalescence was observe्dुd in one region while in the neighbouring orfe, pocks were discrete and sparsely distributed. Apparently some local factor was responsible furr these distribution patterns. Incidentally, a fagal case from whom the only record of palmar poeds was obtained showed coalescence in this region.

The regional distribution of generalized vagGcinia in unvaccinated cases differed from that $.8 \mathrm{f}$ vaccinated cases but was somewhat similar to that reported by Fries and others (1948) in cases ${ }_{0}^{\circ} \mathrm{f}$ eczema vaccinatum who were not vaccinated either. These authors found involvement of the face in all their cases with occasional localization on ine back and abdomen. In the vaccinated cases from the present series, the arm was constantly involvod while the back and the face were less often attacked. These findings are in part in agreement with those of Fonzari (1952) who also observed generaqzed vaccinia in vaccinated patients with pemplimgus foliaceus.

\section{Site of Appearance of the First Lesions}

The site of appearance of the first lesions is interesting in the discussion of the etiology apd pathogenesis of generalized vaccinia although $\Rightarrow$ it has received no attention in previous reports. In the present study it was recorded in 29 cases, one of whom also had atopic dermatitis while the rest were suffering from pemphigus foliaceus. Theire is an apparent difference when patients develop generalized vaccinia after vaccination with 'tak-' are compared with these unvaccinated developed generalized vaccinia through traismission from other cases. In I I cases bearing a ' take' in activity, the vaccinated arm was alwoys the place where the first secondary pocks (generalization lesions) appeared. In four of these cases, pocks simultaneously appeared at plaçes other than the arm such as the back, face, right leg and back and face, respectively (Table \$). In 14 cases who were not vaccinated, the plages where the first lesions appeared were these recorded in Table 3 .

The back and the legs, usually only one of the legs, were the regions where lesions appeared first with more frequency, thus differing from the occurrenee in patients successfully vaccinated. Howevero. if the arm is neglected, the back and the leg wige 
equally frequent in vaccinated patients. This fact and the frequency with which the back and leg were found involved, clearly indicate a predilection of vaccinial pocks for these regions, at least in patients with pemphigus foliaceus. In eleven of the unvaccinated cases, other regions were later involved.

Four cases vaccinated without ' take' presented a peculiar situation since they apparently did not acquire their infection through the vaccination procedure but through contagion. However, two of these showed the first pocks on the vaccinated arm (Table 3) which suggests that the inoculation was successful although the 'take' did not exist or it did not differ from the secondary lesions in morphology (larger size, heavier scabbing and scarring) nor in timing (earlier appearance, later healing).

\section{Clinical Course}

The duration of the clinical picture of vaccinia was very variable although a definite tendency towards limitation of its course and spontaneous regression was apparent. Pocks 'dried up' in three, four or five days in many cases, especially in those with scanty exanthem. This finding is similar to that made by Fonzari (1952) in generalized vaccinia also occuring in patients with pemphigus foliaceus. On the other hand, very severe cases showed duration of two to three weeks which is consistent with what Fries and others (1948) observed in severe cases of eczema vaccinatum. In two fatal cases from the present series, duration of 22 days was observed and in the remaining two fatal cases it was very similar although the exact date of onset was unknown. No case presented the progressive or prolonged form of generalized vaccinia, not even the fatal cases.

Three cases who were not vaccinated reported that lesions of generalized vaccinia appeared

TABLE 3

Areas where the First Pocks Appeared in 29 Cases of Generalized Vaccinia*

\begin{tabular}{|c|c|c|c|c|}
\hline & $\begin{array}{c}\text { Patients } \\
\text { Vaccinated } \\
\text { with } \\
\text { ' Take' } \\
\text { ( I I Cases) }\end{array}$ & $\begin{array}{c}\text { Patients } \\
\text { not } \\
\text { Vaccinated } \\
\text { (14 Cases) }\end{array}$ & $\begin{array}{l}\text { Patients } \\
\text { Vaccinated } \\
\text { without } \\
\text { 'Take' } \\
\text { (4 Cases) }\end{array}$ & Total \\
\hline \begin{tabular}{l} 
Back .. \\
Leg \\
Arm .. \\
Face .. \\
Buttock .. \\
"Extremi- \\
\multicolumn{2}{c}{ ties" .. }
\end{tabular} & $\begin{array}{r}2 \\
1 \\
11 \\
2 \\
0 \\
0\end{array}$ & $\begin{array}{l}5 \\
7 \\
3 \\
2 \\
2\end{array}$ & $\begin{array}{l}\mathbf{1} \\
0 \\
2 \\
2 \\
2 \\
\\
0\end{array}$ & $\begin{array}{r}8 \\
8 \\
16 \\
6 \\
4 \\
\\
1\end{array}$ \\
\hline
\end{tabular}

*In several cases, the first pocks appeared simultaneously in more than one area. simultaneously in several body regions while II cases without ' take' reported a definite sequence in the appearance of pocks in different body regions. In patients who were vaccinated, pocks appeared in the vicinity of the 'take' three or four days after the latter was manifest; soon more lesions appeared in other regions and after a variable interval ended more or less simultaneously with the 'take'. It seems that in vaccinated individuals developing generalized vaccinia, lesions of generalization disappear simultaneously with or even before the primary lesion (the ' take '). These time-relationships for the onset and disappearance of the primary and secondary lesions were investigated and only one case claimed that secondary pocks ended after the 'take'.

\section{Mortality}

Four cases of generalized vaccinia died. Although patients with pemphigus foliaceus usually die from intercurrent diseases such as diarrhoea and tuberculosis, it is believed that vaccinia influenced the four deaths because of: (a) a fatal end of some cases of generalized vaccinia has repeatedly been observed (Clark and others, 1944; McLachlan and Gillespie, 1936; Greenberg, I948; Sommerville, Napier and Dick, 1951); (b) death occurred after a clinical course similar to that reported for fatal generalized vaccinia in persons without pemphigus foliaceus; (c) in all? four fatal cases, the duration of illness was quite uniform; (d) the fatal cases belonged to the first outbreak which suggests the influence of immunity and thus, of vaccinia; (e) no fatal case showed a scanty pock exanthem; (f) the vaccinial eruption was neither healing nor showing signs of regression when death ensued; (g) extensive sepsis of the skin was noticed, a complication similarly reported by others (Fries and others, 1948; McLachlan and Gillespie, 1936; Sommerville and others, I95I) for fatal cases of generalized vaccinia not having pemphigus foliaceus; (h) a severe toxemia, also previously reported for fatal cases (McLachlan and Gillespie, 1936; Sommerville and others, 195I) was observed in two patients who died while the remaining two fatal cases were not followed up.

No fatality was observed in Fries and others (1948) I6 cases of eczema vaccinatum; five of McLachlan and Gillespie (1936) 16 cases of Kaposi's varicelliform eruption died and two out of the 45 cases recorded by Greenberg (1948) had a fatal outcome. Other reports show similarly variable frequencies although mortality is uniformly high in cases of gangrenous vaccinia (Barbero, Gray, McNair Scott and Kempe, 1955). 
Except for one case, no pocks were observed in 媈e

\section{Summary}

Some clinical observations of generalized vaccinia occurring in 47 patients with pemphigus foliaceus were made during two consecutive outbreaks following two mass vaccinations conducted in a pemphigus foliaceus hospital. Virus isolation and/or antibody titration supported the diagnoses based upon clinical and epidemiological data. Four cases died. A continuous gradation in extent and distribution of the exanthem was observed. The pocks first appeared on the back and leg except in vaccinated cases where these lesions always appeared first around the 'take'. Pocks were frequently more abundant on one side of the body and, in some patients, they were clearly unilateral. Pock-confluence was sometimes found on one side and not on the other. palms of the hand or the soles of the feet in a se of 29 cases, not even in those with a profuse exanthem.

Systemic manifestations were constantly $\overrightarrow{\bar{B}} \mathrm{~b}-$ served in a series of 32 cases and the former were independent of the severity of the exanthem. Fever, headache and generalized pains wore observed in $91 \%, 84 \%$ and $31 \%$, respectiv Evidence of a neurological complication tas observed in two cases. A prodromal period Was noticed in three out of nine cases.

Part of this study was supported by Grant E- $\overrightarrow{1 \overrightarrow{3}+3}$ from the U.S. Public Health Service. The facil provided by Dr. João Paulo Vieira as well as the helpof Dr. Ablio F. Martins de Castro, Miss Carmen Espó to and the nurses of the Pemphigus Foliaceus Hospitala gratefully acknowledged.

\section{REFERENCES}

Barbero, G. J., Gray, A., McNair Scott, T. F., and Kempe, C. H. (1955): Vaccinia Gangrenosa Treated with Hyperimmune Vaccinial Gamma Globulin, Pediatrics, 16, 609.

Clark, W. G., Seiler, H. E., Joe, A., Gammie, J. L., TAit, H. P., and Jack, R. P. (r944): The Edinburgh Outbreak of Smallpox, 1942. Edinburgh: City of Edinburgh Public Health Department, p. 43.

Curth, H. O., Curth, W., and GARB, J. (1948): Cutaneous Complications of Mass Vaccination in New York Co. I 947 (Part II), F. invest. Dermat., I1, 167.

Fonzari, M. (1952): Considerações Sôbre a Evolução de um Caso de Pênfigo Foliáceo, Arch. Derm. Sif. S. Paulo, I4ř̃24. Fries, J. H., BorNe, S., and BARNES, H. L. (1948): Varicelliform Eruption of Kaposi Due to Vaccinia Virus Compliogating Atopic Eczema, $\mathcal{Y}$. Pediat., 32, 532.

Greenberg, M. (1948): Complications of Vaccination Against Smallpox, Amer. F. Dis. Child., 76, 492.

Mclachlan, A. D., and Gillespie, M. (1936): Kaposi's Varicelliform Eruption: An Epidemic of Sixteen (6a Brit. F. Derm., 48, 337 .

Sommerville, J., NAPIER, W., and Dick, A. (195I): Kaposi's Varicelliform Eruption: Record of an Outbreak, Ibsad, $63,203$.

Tedder, J. W. (1936): Eczema Vaccinatum, Arch. Derm. Syph. (Chicago), 34, 1008. 